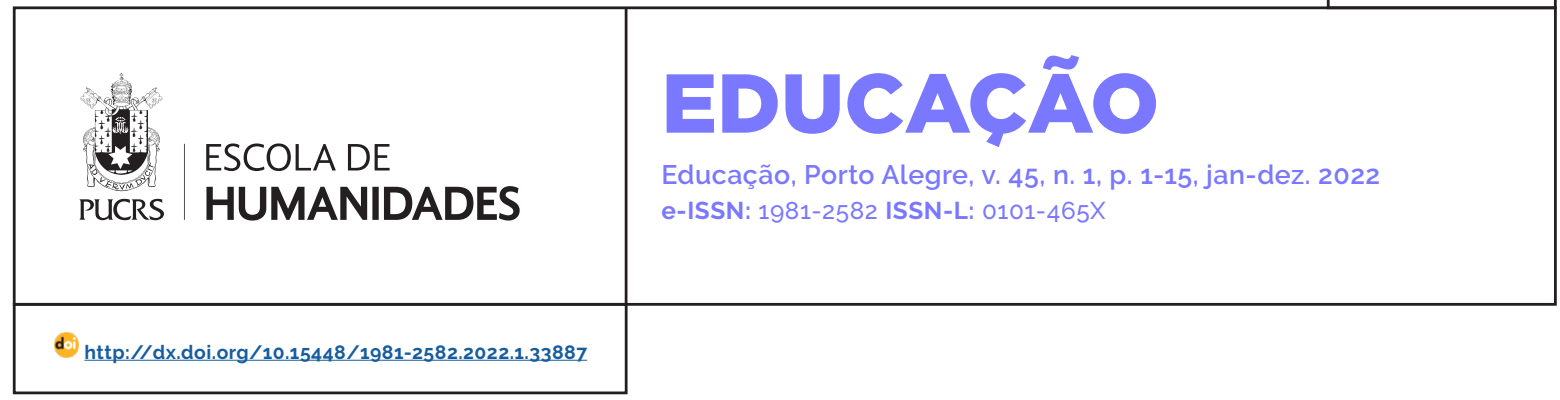

SEÇÃO: ARTIGO

\title{
O direito à educação aos privados de liberdade no Brasil e o papel do FUNPEN no seu financiamento
}

\author{
The right to education for prisoners in Brazil and the role of FUNPEN in its financing \\ El derecho a la educación a los privados de libertad en Brasil y el papel del FUNPEN \\ en su financiación
}

\section{Fabrício Aarão Freire Carvalho ${ }^{1}$}

orcid.org/0000-0002-4753-2560

fafc33@gmail.com

\section{Maria do Socorro da \\ Costa Coelho ${ }^{1}$}

orcid.org/0000-0002-6911-9371

socorrocoelho@gmail.com

\section{Pablo Aguiar Castro \\ Batista ${ }^{2}$}

orcid.org/0000-0001-7805-9553 admpabloaguiar@yahoo.com.br

Recebido em: 10 abr. 2019 Aprovado em: 24 jul. 2021. Publicado em: 8 mar. 2022.

\section{(c) (i)}

Artigo está licenciado sob forma de uma licença Creative Commons Atribuição 4.0 Internacional.
Resumo: Este estudo teve por objetivo analisar o papel do Fundo Penitenciário Nacional (FUNPEN) no financiamento das atividades educacionais, no esforço do Estado brasileiro, em promover a reinserção social dos privados de liberdade no periodo de 2014 a 2018. Trata-se de uma pesquisa quanti-qualitativa pautada na análise de dados estatísticos e financeiros, na revisão bibliográfica e estudo documental do arcabouço legal que orienta o funcionamento do sistema penitenciário e do FUNPEN. A pesquisa revelou que temos um sistema penitenciário com unidades prisionais precárias, superlotadas, sem condições estruturais e de recursos humanos necessários para cumprir o seu papel de reintegração social por meio da educação a um público majoritariamente jovem e com baixa escolaridade, cuja política de financiamento, vem sendo marcada por problemas na fiscalização, no processo de prestação de contas, pelo contingenciamento de seus recursos e consequente desvios de suas finalidades para garantir o superávit primário governamental.

Palavras-chave: privados de liberdade, reinserção social, educação prisional, FUNPEN

Abstract: This study aimed to analyze the role of the National Penitentiary Fund (FUNPEN) in the financing of educational activities, in the effort of the Brazilian State to promote the social reintegration of those deprived of liberty in the period from 2014 to 2018. This is a quantitative end qualitative research based on the analysis of statistical and financial data, on the bibliographical review and documental study of the legal framework that guides the functioning of the penitentiary system and FUNPEN. The research revealed that we have a penitentiary system with precarious, overcrowded prison units, without the structural conditions and human resources necessary to fulfill its role of social reintegration through education. There is a mostly young public with low education, whose funding policy, it has been marked by problems in the inspection, accountability process, the restriction of its resources and the consequent deviations from its purposes to guarantee the government's primary surplus.

Keywords: deprived of liberty, social reinsertion, prison education, FUNPEN

Resumen: Este estudio tuvo como objetivo analizar el papel del Fondo Nacional Penitenciario (FUNPEN) en el financiamiento de las actividades educativas, en el esfuerzo del Estado brasileño para promover la reinserción social de los privados de libertad en el periodo de 2014 a 2018. Investigación cuantitativa-cualitativa basada en el análisis de datos estadisticos y financieros, en la revisión bibliográfica y estudio documental del marco legal que orienta el funcionamiento del sistema penitenciario y FUNPEN. La investigación reveló que tenemos un sistema penitenciario con unidades penitenciarias precarias, superpobladas, sin las condiciones estructurales y los recursos humanos necesarios para cumplir su rol de reinserción social a través de la educación. Hay un público mayoritaria- 
mente joven y con bajo nivel educativo, cuya politica de financiamiento, ha estado marcado por problemas en la fiscalización, el proceso de rendición de cuentas, la restricción de sus recursos y las consecuentes desviaciones de sus propósitos para garantizar el superávit primario del gobierno.

Palabras clave: privados de libertad, reinserción social, educación penitenciaria, FUNPEN

Em tempos de exacerbada polarização política no Brasil em que emergem formas antagônicas de ver e resolver os problemas históricos do país de grande desigualdade social, desigualdade de gênero, violência, saúde e educação, não tem sido incomum, também, questionamentos e afirmações pouco confiáveis que não conseguem ir para além do senso comum no que se refere à "situação real" e aos "gastos" do sistema penitenciário brasileiro e a sua "ineficácia no cumprimento do papel de reinserção social dos apenados/ privados de liberdade".

Em que pese a existência real de problemas, pelos quais o sistema penitenciário brasileiro vem passando - recursos humanos e financeiros, infraestrutura, gestão financeira e carcerária e o atendimento dos direitos sociais (saúde, educação, trabalho e assistência jurídica) -, estes precisam de investigação mais aprofundada e tratamento científico pelas mais variadas áreas do conhecimento (Fidalgo et al., 2017). E, dada a importância da educação no processo reabilitador dos privados de liberdade, faz-se necessário para nós, pesquisadores da área, esclarecer aspectos importantes relacionados à garantia do direito público subjetivo de educação a todos os cidadãos brasileiros e desmistificar uma visão pessimista acerca de seu papel no processo de reinserção social dos apenados, evidenciando também as deficiências do sistema penal que impedem a efetivação desse direito.

Assim, como a garantia deste direito está diretamente ligada à questão financeira e vem sendo questionada pelos segmentos mais conservadores da sociedade, precisamos compreender: quais atividades educacionais vêm sendo ofertadas às pessoas privadas de liberdade atendidas pelo sistema penitenciário brasileiro? Qual a origem dos recursos gastos com o sistema penitenciário brasileiro? Nos últimos anos (2014 a 20183), qual o montante de recursos disponibilizado pelo Fundo Penitenciário Nacional (FUNPEN) e como esse vem sendo gasto? Do montante de recursos disponibilizados, quanto tem sido empregado em atividades de reinserção social - em atividades de formação educacional e cultural - dos privados de liberdade?

Visando responder às questões levantadas, este estudo lança o desafio de analisar o papel do FUNPEN no financiamento das atividades educacionais, no esforço do Estado brasileiro, em promover a reinserção social dos privados de liberdade, no periodo de 2014 a 2018.

O estudo do sistema penitenciário brasileiro, mais especificamente das ações educacionais por ele desenvolvida, bem como de seu financiamento, constitui-se em grande desafio, na medida em que, segundo pesquisa organizada pelo Observatório Nacional do Sistema Prisional (ONASP) da produção stricto sensu (dissertações e teses) sobre a questão penitenciária no país, no periodo de 1987 a 2012, foram encontrado 669 estudos e, deste total, apenas 64 (cerca de 9,6\%) estavam relacionados com a área da educação e nenhum relacionado com a investigação do financiamento desta atividade especificamente (Fidalgo et al., 2017)

Apresenta-se aqui um estudo exploratório que articula uma análise qualitativa da bibliografia pertinente da área (Gomes, 2016; Santos, Rodrigues \& Costa, 2017; Fidalgo et al., 2017; Viana, 2017), análise documental da legislação que orienta o

\footnotetext{
3 Periodo marcado por uma conjuntura econômica e política, em que começam a se fazer sentir no Brasil e na América Latina, os impactos da crise capitalista mundial iniciada em 2008. No mesmo periodo houve a reeleição apertada da Presidenta Dilma em 2014; um golpe parlamentar-judicial-midiático que culminou no impeachment da presidenta em 31 de agosto de 2016; o início de um governo ilegítimo sob a liderança do vice-presidente Temer (2016 a 2018) com a missão de reestruturar o capitalismo brasileiro de acordo com a agenda neoliberal e a aprovação da EC n 95/2016 que instituiu um Novo Regime Fiscal no país em que o orçamento do Poder Executivo não pode ser reajustado por percentuais acima da inflação do ano anterior durante 20 anos (MANCEBO, 2017). Obviamente, essa conjuntura afeta as instituições republicanas e as instituições prisionais em especial, no cumprimento de seu papel social e que, portanto, precisa ser investigado.
} 
funcionamento do sistema penitenciário brasileiro (Lei n 7.210/1984; Resolução do CNPCP nº 03/2009; Resolução CNE/CEB No 2/2010; Lei nº 12.433, de 2011; Decreto $n^{\circ} 7.626 / 2011$; Resolução CNE n4/2016) e do FUNPEN (Lei Complementar n 79/1994; Decreto n 1.093/1994; Medida Provisória n 755/2016; Medida Provisória n 781/2017) e uma análise quantitativa de dados educacionais e financeiros do sistema penitenciário brasileiro.

Para coleta e análise dos dados quantitativos referentes à situação do sistema penitenciário brasileiros nos últimos anos, em que pese a dificuldade de acesso às informações mais detalhadas, a fonte foi o site do Sistema Integrado de Informações Penitenciárias (InfoPen) do Departamento Penitenciário Nacional (DEPEN) ligado ao Ministério da Justiça e Segurança Pública que, sintetiza informações estatísticas e publica relatórios sobre os estabelecimentos penais e a população prisional. ${ }^{4}$ Outra fonte de informação muito importante para o estudo das receitas e gastos ${ }^{5}$ do FUNPEN, foi o site do Portal da Transparência, vinculado ao Ministério da Transparência e Controladoria geral da União.

Para a realização da análise dos dados financeiros do FUNPEN, eles foram corrigidos em relação à inflação. Para tanto, aplicou-se o deflator ${ }^{6}$ INPC (Índice Nacional de Preços ao Consumidor) do Instituto Brasileiro de Geografia e Estatística (IBGE), indice que representa melhor a realidade de um trabalhador médio que utiliza dos serviços e recursos públicos e também utilizado para a correção da complementação da União ao Fundo de Manutenção Desenvolvimento da Educação Básica e de Valorização dos Profissionais da Educação (FUNDEB). O cálculo considerou como mês base (início), o mês de janeiro de cada ano e, como o mês fim, o mês de janeiro de 2019. ${ }^{7}$

O artigo encontra-se estrutura em cinco seções: a primeira é esta introdução em que são apresentadas as questões de investigação, objetivos e aspectos metodológicos do estudo; na segunda é apresentado o arcabouço legal que garante e orienta a oferta e o funcionamento das atividades educacionais dentro das unidades prisionais, bem como o seu papel no processo de humanização e reabilitação dos privados de liberdade. Na terceira, a partir de dados quantitativos referentes ao sistema prisional brasileiro, bem como das atividades educacionais ali desenvolvidas, traçamos um breve diagnóstico dessa realidade, identificando suas deficiências e alguns dos principais desafios relacionados à garantia da educação, como instrumento de reinserção social aos privados de liberdade. Na quarta seção, identificamos as fontes de recursos e gastos em atividades de reinserção social - formação educacional - realizadas com os recursos do FUNPEN, avaliando o seu volume de gastos e importância dentro do conjunto de gastos com o sistema prisional e, por fim, a quinta e última seção com as considerações finais.

\section{Do direito à educação aos privados de liberdade}

Para início de conversa, é importante lembrar que, conforme assegurado pelo próprio texto constitucional da República Federativa do Brasil, vivemos sob um "Estado Democrático de Direito" que tem como um de seus fundamentos assegurar a "dignidade da pessoa humana" (Brasil, 1988, art. $1^{\circ}$, III) e a construção de uma "sociedade livre, justa e solidária" (Brasil, 1988, art. 3º, I). E, a educação neste cenário, está inserida no rol dos direitos sociais, como

direito de todos e dever do Estado e da família, será promovida e incentivada com a colaboração da sociedade, visando ao pleno desenvolvimento da pessoa, seu preparo para o exercicio da cidadania e sua qualificação para o trabalho. (Brasil, 1988, art. 205, grifo nosso)

A educação, portanto, conforme reiterado também por nossa lei máxima da educação (Lei n 9.394/1996), é um direito universal do qual

\footnotetext{
4 Até o momento de conclusão da pesquisa, o Infopen só havia disponibilizado relatório do sistema prisional brasileiro até o ano de 2016

5 Para a análise dos dados financeiros foram trabalhados os quatro últimos anos de dados disponiveis, 2014 a 2018.

- O deflator é um índice utilizado para equiparar valores monetários de diversas épocas ao valor monetário de uma determinada época tomada como ano base.

7 O índice utilizado ano a ano foi calculado por meio de instrumento on line denominado "Calculadora do cidadão" disponível no site do Banco Central.
} 
todos os seres humanos são titulares, estejam eles dentro ou fora das prisões. Ainda segundo o texto constitucional, a educação básica gratuita é obrigatória para a população de 4 a 17 anos de idade, sendo também assegurada àqueles que a ela não tiveram acesso na idade própria (art. 208 da $\left.^{(2}{ }^{8}\right)$, e isso inclui as pessoas privadas de liberdade pois segundo Viana, "o cárcere, priva o indivíduo de seu direito de ir e vir, mas seus outros direitos devem ser preservados na máxima medida possivel, desde que não atingidos pela condenação" (2017, p. 95).

Para além das normativas nacionais mais amplas, no cenário internacional há um conjunto de instrumentos normativos que consagram a educação como direito a exemplo da Declaração Universal dos Direitos Humanos (ONU, 1948) e o Protocolo Adicional à Convenção Americana de Direitos Humanos (OEA, 1988)

Ainda de acordo com Viana, além desses dois instrumentos ratificados pelo Brasil,

pode-se identificar mais especificamente a proteção ao trabalho e à educação no contexto prisional, a partir dos Princípios Básicos ao Tratamento de Reclusos estabelecidos no anexo da Resolução n 45/111 da Assembleia Geral da Organização das Nações Unidas (ONU) de dezembro de 1990, tais normas, em especial as de número, 6, 8 e 10, garantem aos presos o direito de participarem de atividades culturais e educacionais voltadas para o desenvolvimento de sua personalidade e de realizarem trabalhos recebendo remuneração significativa, visando à criação de condições que favoreçam a sua reinserção no mercado de trabalho, no seio de sua própria familia e, em última análise, na sociedade. (2017, p. 96)

Vale destacar que o Brasil, antes mesmo da aprovação de nossa Constituição cidadã em 1988, já possuia um instrumento normativo mais específico "teoricamente bem-formatado" e capaz de viabilizar a efetivação das regras e princípios que o sistema internacional de direitos humanos da Organização das Nações Unidas (ONU) e seus órgãos, determinavam (Viana, 2017).

Em 1940, o Código Penal regulamentado pelo Decreto-Lei $n^{\circ}$ 2.848, ao tratar dos Direitos do preso em seu art. 38, fixava que este "conservava todos os direitos não atingidos pela perda de liberdade, impondo-se a todas as autoridades o respeito à sua integridade física e moral".

Em 1984, ano de grandes manifestações políticas pró-democracia no Brasil, marcado pelo fim da Ditadura Militar e pela realização de eleição presidencial indireta, foi aprovada a Lei de Execução Penal (LEP), Lei n 7.210/1984 que refuta a antiga condição da prisão como depósito de dejetos humanos em favor de uma tendência mais humanista e de ideal reabilitador.

Segundo o próprio texto da LEP,

\begin{abstract}
A execução penal tem por objetivo efetivar as disposições de sentença ou decisão criminal e proporcionar condições para a harmônica integração social do condenado e do internado. A assistência ao preso e ao internado é dever do Estado, objetivando prevenir o crime e orientar o retorno à convivência em sociedade. A assistência será: material; à saúde; jurídica; social; religiosa; educacional; A assistência educacional compreenderá a instrução escolar e a formação profissional do preso e do internado. $O$ ensino de $1^{\circ}$ grau será obrigatório, integrando-se no sistema escolar da Unidade Federativa. O ensino profissional será ministrado em nivel de iniciação ou de aperfeiçoamento técnico (Brasil, 1984, art. $1^{\circ}$, p. 10, 11, 17-19)
\end{abstract}

Nos anos seguintes, um conjunto novo de legislações foram aprovadas e garantiram aos privados de liberdade, o direito à educação e regulamentaram melhor a forma de materialização desse direito nas unidades prisionais. A Resolução do Conselho Nacional de Política Criminal e Penitenciária (CNPCP) no 14/1994, ao definir as Regras Mínimas para o Tratamento do Preso no Brasil fixou "jornada de trabalho diária e semanal para os condenados, observada a destinação de tempo para lazer, descanso. Educação e outras atividades que se exigem como parte do tratamento e com vistas a reinserção social" (Brasil, 1994, cap. XXI, inciso VII).

A Resolução do CNPCP nº 03/2009, ao dispor sobre as Diretrizes Nacionais para a Oferta de Educação nos estabelecimentos penais, definiu que esta deve ser contemplada com as devidas oportunidades de financiamento junto aos órgãos estaduais e federais, como desenvolvimento de

8 Redação dada pela EC n 59/2009 
atividades de educação formal, propostas de educação não formal e formação profissional, bem como a inclusão da modalidade de educação a distância, com a definição de calendário comum aos estabelecimentos penais onde houver oferta (Brasil, 2009, art. 3․ p. 10).

Ao tratar mais especificamente das Diretrizes Nacionais para a oferta de educação para jovens e adultos nos estabelecimentos penais, a Resolução CNE/CEB No 2/2010 estabelece que é atribuição do órgão responsável pela educação nos Estados e no Distrito Federal (Secretaria de Educação ou órgão equivalente) e deverá ser realizada em articulação com os órgãos responsáveis pela sua Administração Penitenciária, exceto nas penitenciárias federais, cujos programas educacionais estarão sob a responsabilidade do Ministério da Educação em articulação com o Ministério da Justiça, que poderá celebrar convênios com Estados, Distrito Federal e Municípios (Brasil, art. 3 , 2010).

A remição por estudo é uma medida mais recente, e foi instituída por meio da Lei n 12.433 , de 2011. De acordo com esta normativa, a cada $12 \mathrm{~h}$ de frequência escolar, divididas em pelo menos três dias, dão direito à remissão de um dia de pena e em caso de conclusão do ensino fundamental, médio ou superior o apenado terá um terço do tempo remido (Viana, 2017).

Ainda em 2011, o Decreto n 7.626/2011 instituiu o Plano Estratégico de Educação no âmbito do Sistema Prisional (PEESP) com a finalidade de ampliar e qualificar a oferta de educação nos estabelecimentos penais. Contempla a educação básica na modalidade de educação de jovens e adultos, a educação profissional e tecnológica, e a educação superior. Tem por objetivos:

I - executar ações conjuntas e troca de informações entre órgãos federais, estaduais e do Distrito Federal com atribuições nas áreas de educação e de execução penal; II - incentivar a elaboração de planos estaduais de edu- cação para o sistema prisional, abrangendo metas e estratégias de formação educacional da população carcerária e dos profissionais envolvidos em sua implementação; III - contribuir para a universalização da alfabetização e para a ampliação da oferta da educação no sistema prisional; IV - fortalecer a integração da educação profissional e tecnológica com a educação de jovens e adultos no sistema prisional; $\vee$ - promover a formação e capacitação dos profissionais envolvidos na implementação do ensino nos estabelecimentos penais; e VI - viabilizar as condições para a continuidade dos estudos dos egressos do sistema prisional. (Brasil, 2011, art. $4^{\circ}$ )

Em 2016, foi publicada a Resolução CNE n 4/2016, que dispõe sobre as Diretrizes Operacionais Nacionais para a remição de pena por meio do estudo para pessoas em privação de liberdade nos estabelecimentos penais do sistema prisional brasileiro. Essa Resolução, segundo Gomes, estabeleceu que a oferta de programas de EJA e qualificação profissional, para fins de remição de pena em estabelecimentos penais, "pode ocorrer na forma presencial ou na modalidade a distância, ou ainda em uma combinação de ambos, desde que supervisionadas pelos sistemas de ensino" (Gomes, 2016, p. 14)

\section{O sistema prisional brasileiro: características e desafios em termos de formação educacional como atividade de reinserção social}

Para que possamos iniciar nossas análises acerca do sistema penitenciário brasileiro e da importância de seu papel no processo de reinserção social dos privados de liberdade por meio da educação, precisamos minimamente compreender como está e, vem se configurando, o perfil da população carcerária nos últimos anos. A Tabela 1, a seguir, apresenta dados de população, número de vagas e total de estabelecimentos penais no periodo de 2014 a 2016.

TABELA 1 - Dados de população dos privados de liberdade, número de vagas e total de estabelecimentos penais no Brasil - 2014 a 2016

\begin{tabular}{|c|c|c|c|}
\hline Dados gerais & $\mathbf{2 0 1 4}$ & $\mathbf{2 0 1 5}$ & $\mathbf{2 0 1 6}$ \\
\hline População privados de liberdade $^{*}$ & 622.202 & 698.618 & 726.712 \\
\hline Número de habitantes* $^{*}$ & 203.190 .852 & 204.450 .649 & 206.081 .432 \\
\hline
\end{tabular}




\begin{tabular}{|c|c|c|c|}
\hline População carcerária por 100.000 habitantes & 306,2 & 341,7 & 352,6 \\
\hline Número de vagas (sistema penitenciário) & 371.884 & 371.201 & 368.049 \\
\hline Total de estabelecimentos penais & 1.436 & 1.414 & 1.422 \\
\hline
\end{tabular}

Fonte: *IBGE - Pesquisa Nacional por Amostra de Domicilios, 2014-2016. Ministério da Justiça. Departamento Penitenciário Nacional. Sistema Integrado de Informações Penitenciárias - InfoPen, 2014 a 2016.

A partir dos dados apresentados na Tabela 1 é possivel perceber que, no periodo analisado, houve crescimento de $16,8 \%$ da população privada de liberdade. Em 2014 tínhamos 306,2 pessoas privadas de liberdade para cada cem mil habitantes e saltamos para o patamar de 352, 6 em 2016. Na contramão desses dados, tivemos redução de
1,0\% tanto no número de vagas quanto no número de estabelecimentos penais no mesmo periodo. O que torna evidente o problema de superlotação dos presidios.

As tabelas 2 e 3, a seguir, apresentam informações que nos ajudam a traçar o perfil da população privada de liberdade.

TABELA 2 - Dados de pessoas privadas de liberdade por faixa etária no Brasil - 2014 a 2016

\begin{tabular}{|c|c|c|c|}
\hline Faixa etária & $\mathbf{2 0 1 4}$ & $\mathbf{2 0 1 5}$ & $\mathbf{2 0 1 6}$ \\
\hline 18 a 24 anos & 158.185 & 139.811 & 155.976 \\
\hline 25 a 29 anos & 131.119 & 118.884 & 126.540 \\
\hline 30 a 34 anos & 99.487 & 92.433 & 96.243 \\
\hline 35 a 45 anos & 95.600 & 92.150 & 96.229 \\
\hline 46 a 60 anos & 35.453 & 33.507 & 34.309 \\
\hline 61 a 70 anos & 4.989 & 4.797 & 5.132 \\
\hline Mais de 70 anos & 651 & 690 & 759 \\
\hline Não informado & 59.274 & 180.883 & 174.759 \\
\hline
\end{tabular}

Fonte: Ministério da Justiça. Departamento Penitenciário Nacional. Sistema Integrado de Informações Penitenciárias - InfoPen, 2014 a 2016.

A partir dos dados da Tabela 2, é possivel constatar que se trata de uma população predominantemente jovem (18 a 29) que, ao longo da série histórica apresentada vem representando, em média, 43,1\% do total dos presos. Ou seja, é uma população concentrada dentro da faixa etária da população economicamente ativa, que possui enorme potencial de mão de obra e que deveriam estar produzindo para o país, mas que, por fatores econômicos, sociais e de emprego, dentre outros, cometeram algum delito e foram punidos com a privação de sua liberdade.

Os dados apresentados na Tabela 3, acrescentam mais um elemento importante para nossa compreensão do perfil dessa população:

TABELA 3 - Dados de população dos privados de liberdade por grau de instrução no Brasil - 2014 a 2016

\begin{tabular}{|c|c|c|c|}
\hline Grau de instrução & $\mathbf{2 0 1 4}$ & $\mathbf{2 0 1 5}$ & $\mathbf{2 0 1 6}$ \\
\hline Analfabeto & 19.487 & 17.847 & 16.976 \\
\hline Alfabetizado sem cursos regulares & 32.880 & 31.165 & 28.953 \\
\hline Ensino fundamental incompleto & 242.222 & 229.735 & 247.158 \\
\hline Ensino fundamental completo & 72.216 & 61.642 & 67.963 \\
\hline Ensino médio incompleto & 68.192 & 65.321 & 70.076 \\
\hline Ensino médio completo & 46.602 & 41.783 & 45.192 \\
\hline Ensino superior incompleto & 4.623 & 4.173 & 4.241 \\
\hline Ensino superior completo & 2.253 & 2.126 & 2.243 \\
\hline
\end{tabular}




\begin{tabular}{|c|c|c|c|}
\hline Ensino acima de superior completo & 107 & 95 & 80 \\
\hline Não informado & 96.176 & 209.268 & 207.065 \\
\hline
\end{tabular}

Fonte: Ministério da Justiça. Departamento Penitenciário Nacional. Sistema Integrado de Informações Penitenciárias - InfoPen, 2014 a 2016.

Observa-se que, além de jovem, a população é predominantemente pouco instruída, composta por analfabetos ou que possuem apenas o ensino fundamental incompleto/completo. Ao longo do periodo analisado, a quantidade de presos com o ensino fundamental incompleto representou, em média, 37.3\% do total presos. Essas carac teristicas, impõem ao sistema prisional, criar a estrutura fisica necessária para desenvolver ações de formação educacional e contratar profissionais da área da educação visando a reinserção social dessas pessoas.

Em relação a estes aspectos, as tabelas 4 e 5 apresentam a seguinte situação:

TABELA 4 - Quantidade de unidades prisionais no Brasil com espaços educacionais - 2014 a 2016

\begin{tabular}{|c|c|c|c|c|c|c|}
\hline \multirow{2}{*}{ Espaços educacionais } & \multicolumn{2}{|c|}{2014} & \multicolumn{2}{c|}{2015} & \multicolumn{2}{c|}{2016} \\
\cline { 2 - 7 } & $\mathrm{N}^{\circ}$ & $\%$ & $\mathrm{~N}^{\circ}$ & $\%$ & $\mathrm{~N}^{\circ}$ & $\%$ \\
\hline Estabelecimentos com sala de aula & 819 & 57 & 819 & 58 & 823 & 58 \\
\hline Estabelecimentos com sala de informática & 169 & 12 & 157 & 11 & 168 & 12 \\
\hline $\begin{array}{c}\text { Estabelecimentos com sala de encontros } \\
\text { com a sociedade/ sala de reuniões }\end{array}$ & 229 & 16 & 267 & 19 & 281 & 20 \\
\hline Estabelecimentos com biblioteca & 611 & 43 & 572 & 40 & 593 & 42 \\
\hline Estabelecimentos com sala de professores & 372 & 26 & 369 & 26 & 383 & 27 \\
\hline Estabelecimentos com outros espaços de & 60 & 4 & - & - & - & - \\
\hline
\end{tabular}

Fonte: Ministério da Justiça. Departamento Penitenciário Nacional. Sistema Integrado de Informações Penitenciárias - InfoPen, 2014 a 2016

Conforme podemos perceber, pouco mais da metade (em média $57,7 \%$ ) das unidades prisionais do Brasil, possuem espaços reservados para realização das aulas, apenas $11,7 \%$ (em média) possuem sala de informática e apenas $41,7 \%$ das unidades prisionais possuem biblioteca. Em que pese o direito à educação aparecer garantido no arcabouço legal do sistema penitenciário brasi leiro desde 1984, quer dizer, há cerca de 34 anos atrás, ainda temos muito a avançar no sentido de garantir este direito.

A importância do desenvolvimento desta atividade não tem se feito refletir no processo de contratação de profissionais da área da educação para atuar na educação prisional. conforme dados da Tabela 5:

TABELA 5 - No de profissionais da área da educação que atuam no sistema penal brasileiro - 2014 a 2016

\begin{tabular}{|c|c|c|c|}
\hline Profissionais da Educação & $\mathbf{2 0 1 4}$ & $\mathbf{2 0 1 5}$ & $\mathbf{2 0 1 6}$ \\
\hline Pedagogo & 298 & 276 & 278 \\
\hline Professor & 3.892 & 2.881 & 2.860 \\
\hline Total profissionais da educação & 4.190 & 3.157 & 3.138 \\
\hline Total geral de trabalhadores & 108.093 & 106.111 & 105.921 \\
\hline $\begin{array}{c}\text { \% de Trabalhadores da educação/ total de } \\
\text { trabalhadores }\end{array}$ & 3.9 & 2.9 & 2.9 \\
\hline
\end{tabular}

Fonte: Ministério da Justiça. Departamento Penitenciário Nacional. Sistema Integrado de Informações Penitenciárias - InfoPen, 2014 a 2016. 
O número de profissionais teve uma redução de mais de mil professores do ano de 2014 para o ano de 2015, queda de 1,0\% do total de trabalhadores da educação em relação ao total de trabalhadores das unidades prisionais. Essa redução tende a repercutir negativamente na oferta de atividades de formação educacional aos privados de liberdade.
A análise dos dados sobre a quantidade de pessoas que estão em atividades educacionais nas unidades prisionais, conforme apresentado na Tabela 6, quando comparado com a quantidade de privados de liberdade que precisam de formação, conforme apresentado anteriormente na Tabela 3, são alarmantes e muito preocupantes.

TABELA 6 - Dados de pessoas privadas de liberdade em atividades educacionais* no sistema penitenciário brasileiro - 2014 a 2016

\begin{tabular}{|c|c|c|c|}
\hline Atividades educacionais & $\mathbf{2 0 1 4}$ & $\mathbf{2 0 1 5}$ & $\mathbf{2 0 1 6}$ \\
\hline Alfabetização & 10.800 & 10.867 & 9.851 \\
\hline Ensino fundamental & 32.357 & 30.463 & 14.175 \\
\hline Ensino médio & 12.292 & 13.746 & 554 \\
\hline Ensino superior & 313 & 476 & 623 \\
\hline $\begin{array}{c}\text { Curso de formação inicial e continuada (ca- } \\
\text { pacitação profissional acima de 16oh aula) }\end{array}$ & 7.445 & 748 & 5.138 \\
\hline $\begin{array}{c}\text { Matriculados em programas de remissão } \\
\text { pelo estudo através da leitura }\end{array}$ & 4.587 & 4.743 & 171 \\
\hline $\begin{array}{c}\text { Matriculados em programas de remissão } \\
\text { pelo estudo através do esporte }\end{array}$ & 30 & 3.932 & 7.455 \\
\hline $\begin{array}{c}\text { Envolvidas em atividades educacionais com- } \\
\text { plementares (videoteca, lazer e cultura) }\end{array}$ & 5.751 & 474 & \\
\hline Total geral & 74.436 & $\mathbf{7 2 . 0 9 2}$ & $\mathbf{7 5 . 1 7 3}$ \\
\hline
\end{tabular}

Fonte: Ministério da Justiça. Departamento Penitenciário Nacional. Sistema Integrado de Informações Penitenciárias - InfoPen, 2014 a 2016. *Presenciais e a distância.

Ao longo da série histórica analisada temos, em média, pouco mais de dez mil detentos em atividades de alfabetização para uma demanda média girando em torno de dezoito mil; temos, em média, cerca de trinta e um mil detentos em atividade educacional no ensino fundamental para uma demanda média de cerca de duzentos e trinta e nove mil detentos, ou seja, quando focalizamos nossa atenção apenas para as ativi dades educacionais em nivel de alfabetização e de ensino fundamental percebemos que o déficit em termos de atendimento pelas unidades penais é muito elevado, girando em torno de $45 \%$ e $87 \%$ respectivamente.

Esta grave situação é parcialmente explicada quando consideramos que, conforme evidenciado pelos dados da Tabela 7, pouco mais da metade das unidades prisionais, em média 55.3\%, possuem privados de liberdade estudando.

TABELA 7 - Número de unidades prisionais com privados de liberdade estudando - 2014 a 2016

\begin{tabular}{|c|c|c|c|c|c|c|}
\hline \multirow{2}{*}{ Estabelecimentos } & \multicolumn{2}{|c|}{2014} & \multicolumn{2}{|c|}{2015} & \multicolumn{2}{c|}{2016} \\
\cline { 2 - 7 } & $N^{\circ}$ & $\%$ & $N^{\circ}$ & $\%$ & $N^{\circ}$ & $\%$ \\
\hline Com pessoas estudando & 754 & $53 \%$ & 797 & $56 \%$ & 810 & $57 \%$ \\
\hline Sem pessoas estudando & 682 & $47 \%$ & 617 & $44 \%$ & 610 & $43 \%$ \\
\hline
\end{tabular}




\begin{tabular}{|l|l|l|l|l|l|l} 
Não informado & 0 & $0 \%$ & - & $0 \%$ & 2 & $0 \%$ \\
\hline
\end{tabular}

Fonte: Ministério da Justiça. Departamento Penitenciário Nacional. Sistema Integrado de Informações Penitenciárias - InfoPen, 2014 a 2016.

No geral, os dados apresentados evidenciam a superlotação dos estabelecimentos penais compostos por um público majoritariamente jovem e com baixa escolaridade. Evidenciam, também, que o sistema penitenciário não tem conseguido - em termos de infraestrutura e de recursos humanos capacitados na área da educação - criar as condições de infraestrutura necessárias para dar conta da missão última de promover a reinserção social do preso, por meio da educação. O que impõe ao sistema o grande desafio e necessidade de investir, desenvolver e ampliar as ações de reinserção social, de formação educacional, profissional e cultural aos privados de liberdade. No atual cenário político-econômico, está posto ao Estado brasileiro o grande desafio de não apenas proteger e garantir os direitos humanos na letra da lei, mas o de efetivá-los no âmbito das políticas públicas sociais e educacionais.

Para dar conta destes e de outros desafios, são necessários investimentos financeiros por parte do Estado brasileiro. Contudo, esses foram definidos apenas dez anos depois da promulgação da LEP, com a criação do Fundo Penitenciário Nacional (FUNPEN) em 1994, no intuito de dar condições financeiras às Unidades da Federação para arcar com a manutenção e o aprimoramento de seus sistemas prisionais. Assim, cabe perguntar nos últimos anos qual o montante de recursos disponibilizado pelo Fundo Penitenciário Nacional (FUNPEN) e como esse vem sendo gasto? Do montante de recursos disponibilizados, quanto tem sido empregado em atividades de reinserção social - em atividades de formação educacional e cultural - dos privados de liberdade? Essas e outras questões serão respondidas ao longo do texto.

\section{O FUNPEN: fontes de recursos e gastos em atividades de reinserção social - formação educacional}

O sistema prisional brasileiro é formado por penitenciárias federais que estão sob a responsabilidade da União e por penitenciárias estaduais que estão sob responsabilidade de cada ente da federação.

Para a sua manutenção, o Sistema Prisional brasileiro conta com recursos originários do Fundo Penitenciário Nacional (FUNPEN9), criado pela Lei Complementar $n^{\circ} 79$ de 07 de janeiro de $1994,{ }^{10}$ regulamentado pelo Decreto executivo $n^{\circ}$ 1.093, de 23 de março de 1994 e diretamente vinculado à estrutura do Ministério da Justiça e Segurança Pública. Trata-se de um fundo de natureza contábil que integra o orçamento fiscal da União que, repassa aos fundos dos Estados, do Distrito Federal e Municipios, por meio de convênios, percentuais da dotação orçamentária do FUNPEN (Brasil, 1994, art. 30).11

De acordo com Souza (2017), em que pese a gestão das unidades prisionais ser de responsabilidade dos estados - com exceção das Unidades prisionais federais -, os elevados custos do sistema penitenciário dificultam sua administração e, sem apoio da União, os estados, sozinhos, não conseguem arcar com todos os custos do sistema, e por isso, parte dos recursos do FUNPEN são repassados aos Fundos Penitenciários Estadu-

\footnotetext{
9 Em consonância com os artigos 71 a 74 que tratam dos Fundos Especiais, da Lei n 4.320/1964: "Constitui fundo especial o produto de receitas especificadas que por lei se vinculam à realização de determinados objetivos, facultada a adoção de normas peculiares de aplicação".

10 Modificada pela Medida Provisória n 755/2016. Autorizou o descontingenciamento das verbas do FUNPEN e expandiu o campo sobre o qual podem ser aplicados os recursos do fundo para além de sua previsão inicial, incluindo notoriamente ações vinculadas à segurança pública e de cunho preponderantemente repressivo. Pela Nova Medida Provisória n $781 / 2017$ que revogou integralmente a MPV n 755, estabeleceu a redação vigente da Lei Complementar n 79/1994, estabeleceu a descentralização dos recursos de forma progressiva entre 2016 e 2018, vedou a prática de contingenciamento com suas verbas e reintegrou as fontes de arrecadação do Fundo oriundas de loterias federais, mas manteve as modalidades vinculadas a politicas repressivas.

${ }_{11}$ Alterada mais recentemente pela Lei $n^{\circ} 13.500$ de 26 de outubro de 2017 que prevê o repasse de recursos para os fundos dos Estados, do Distrito Federal e dos Municipios a título de transferência obrigatória e independentemente de convênio ou de instrumento congênere.
} 
ais $^{12}$ (FUNPES). E, ainda que estes se constituam como maior parte da verba, os Estados contam com outras arrecadações, como doações, multas decorrentes de sentenças penais, fianças quebradas ou perdidas, parcela descontada da remuneração do trabalho dos detentos, parte da receita da venda de bens produzidos nas unidades penais do estado, entre outros.

Segundo a Lei Complementar n 79/1994, os recursos do FUNPEN são geridos pelo Departamento Penitenciário Nacional (DEPEN) e são constituidos de recursos provenientes das dotações orçamentárias, custas judiciais recolhidas em favor da União, arrecadação dos concursos de prognósticos, recursos confiscados ou provenientes da alienação dos bens perdidos em favor da União, multas de sentenças penais condenatórias com trânsito em julgado, fianças quebradas ou perdidas, e rendimentos decorrentes da aplicação de seu patrimônio (Brasil, 1994. art. $1^{\circ}$ e $2^{\circ}$ ).

A partir destas fontes, o FUNPEN tem contabilizado sua arrecadação de recursos. Entre os anos de 1999 e 2011, por exemplo, "O FUNPEN guarneceu-se de R\$ 2.991.401.324,71, ou seja, aproximadamente três bilhões de reais, tendo esses valores crescido ainda mais nos anos subsequentes" (Brasil, 2017, p. 15). No período de aproximadamente doze anos, o sistema penitenciário brasileiro "teve" em média cerca de 250 milhões/ano para, entre outras ações, promover a reintegração social dos apenados por meio da educação. Valor este que, se dividido pelos 514. 6 mil presos de 2011 (Erdelyi, 2017) chegariamos ao valor de $\mathrm{R} \$ 485,00$ investidos por preso/ano, valor quase quatro vezes menor ao estabelecido pelo FUNDEB por aluno/ano da educação básica que em 2011 foi de $\mathrm{R} \$ 1.722,05$

Ainda segundo esta lei, os recursos do FUNPEN deverão ser aplicados, dentre outros aspectos, em: formação, aperfeiçoamento e especialização do serviço penitenciário; formação educacional e cultural dos presos, na elaboração e execução de projetos destinados à reinserção social de presos, internados e egressos, inclusive por meio da realização de cursos técnicos e profissionalizantes e programas de alternativas penais à prisão (Brasil, art. $3^{\circ}$, incisos III; VI, VII e XVI).

Como fonte adicional de recursos para o desenvolvimento de atividades de formação educacional destinada aos privados de liberdade, a Resolução CNE/CEB No 2/2010 que dispõe sobre as Diretrizes Nacionais para a oferta de educação de jovens e adultos em situação de privação de liberdade nos estabelecimentos penais, prevê a possibilidade de utilização de fontes de recursos públicos vinculados à manutenção e ao desenvolvimento do ensino, entre as quais o Fundo de Manutenção e Desenvolvimento da Educação Básica e de Valorização dos Profissionais da Educação (FUNDEB).

Tratando mais especificamente dos recursos do FUNPEN, objeto de estudo desta seção do artigo, de acordo com o Relatório Temático: FUNPEN e Prevenção à Tortura no Brasil, elaborado pelo MNPCT (Mecanismo Nacional de Prevenção e Combate à Tortura - órgão federal instituído pela Lei $n^{\circ} 12.847$, de 2 de agosto de 2013), a existência deste fundo vem sendo marcada por vários problemas que, acabam interferindo negativamente no cumprimento de suas finalidades, tais como: o "contingenciamento orçamentário, mau planejamento, ineficiência na alocação de recursos, falta de prestação de contas, ausência de condições técnicas de execução pelos entes federados recebedores dos recursos e fiscalização ineficaz da aplicação dos mesmos" (Brasil, 2017, p. 17).

Segundo o Relatório, o provisionamento dos recursos do FUNPEN é feito por meio de transferências voluntárias e, por não decorrerem de obrigações estabelecidas constitucionalmente,

12 Segundo a Lei $n^{\circ} 13.500$ de 26 de outubro de 2017, para recebimento dos recursos na modalidade fundo a fundo devem ser observados os requisitos constantes em seu art. $3^{\circ} \mathrm{A}, \S 3^{\circ}$, quais sejam: I - existência de fundo penitenciário, no caso dos Estados e do DF, e de fundo específico, no caso dos Municipios; II - existência de órgão ou de entidade especifica responsável pela gestão do fundo de que trata o inciso I deste parágrafo; III - apresentação de planos associados aos programas a que se refere o $\S 20$ deste artigo, dos quais constarão a contrapartida do ente federativo, segundo critérios e condições definidos, quando exigidos em ato do Ministro de Estado da Justiça e Segurança Pública; IV - habilitação do ente federativo nos programas instituídos; V - aprovação de relatório anual de gestão, o qual conterá dados sobre a quantidade de presos, com classificação por sexo, etnia, faixa etária, escolaridade, exercício de atividade de trabalho, estabelecimento penal, motivo, regime e duração da prisão, entre outros a serem definidos em regulamento; e VI - existência de conselhos estadual ou distrital penitenciários, de segurança pública. 
permite o uso das dotações orçamentárias do fundo para fins de obtenção do superávit primário. Em função disso, o montante financeiro vinha sendo, desde a criação do Fundo, seguidamente contingenciado e consequentemente não aplicado nas finalidades prevista na legislação (Brasil, 2017). Segundo o relatório,

Em 2013, por exemplo, mais de 80\% dos valores do FUNPEN estiveram contingenciados, permanecendo sem qualquer utilização, resultando em saldo da ordem de bilhões de reais. Segundo o DEPEN, este contingenciamento tinha um papel importante no equilibrio das contas públicas federais, mantendo um compasso entre a realização dos gastos e a arrecadação das receitas de forma a garantir o cumprimento das metas de superávit primário. (Brasil, 2017, p. 16)

Ainda segundo o mesmo relatório, o controle dos recursos era posto em prática por meio de Decretos de Contingenciamento da Presidência da República a cada ano. Contudo, em 2015, o Supremo Tribunal Federal (STF) ao julgar a Ação de Descumprimento de Preceito Fundamental (ADPF) n 347, determinou o descontingenciamento das verbas do FUNPEN, o que "proporcionou ao sistema penitenciário dos estados e do Distrito Federal substanciais recursos financeiros, oriundos do Fundo Penitenciário Nacional (FUNPEN), os quais somaram aproximadamente R \$ 1,1 bilhão" (Brasil, 2017, p. 16).

Outro aspecto problemático acerca do funcionamento do FUNPEN está ligado à sua forma de gestão que destoa da forma de gestão dos fundos penitenciários estaduais e de outros fundos, à exemplo do FUNDEB. ${ }^{13}$ Os recursos do FUNPEN, são administrados unilateralmente pelo DEPEN, por somente um órgão dentro de um ministério, no âmbito da Administração federal, sem a participação de um conselho plural composto por diferentes órgãos públicos e representantes da sociedade civil (Brasil, 2017).

Este conjunto de problemas existentes na forma de gestão dos recursos do FUNPEN acabam por se refletir nos números e no processo de prestação de contas disponíveis no site do portal da transparência, conforme se verificará mais adiante.

Contudo, antes de tratarmos mais detidamente dos recursos do FUNPEN, faz-se necessário, ainda que de forma panorâmica, identificar as despesas do Ministério da Justiça e Segurança Pública por função ${ }^{14}$ ou área de atuação, para posteriormente analisarmos a importância assumida pela função "Direitos da Cidadania" no contexto dos gastos orçamentários deste Ministério e, em seguida, compreendermos a importância dos recursos do FUNPEN nas despesas com essa função e, mais precisamente, com a subfunção "Custódia e reintegração social". Função e subfunção estas, onde encontram-se agregadas, entre outras despesas, as despesas com formação educacional e cultural dos presos, na elaboração e na execução de projetos destinados à reinserção social de presos, internados e egressos, com a realização de c

ursos técnicos, profissionalizantes e programas de alternativas penais à prisão.

A Tabela 8 apresenta os dados de despesa do Ministério da Justiça e Segurança Pública por função durante o período de 2014 a 2018.

TABELA 8 - Despesas do Ministério da Justiça e Segurança Pública do Brasil por área de atuação/FUNÇÃO $2014-2018$

\begin{tabular}{|c|c|c|c|c|c|}
\hline \multirow{2}{*}{ Função } & \multicolumn{5}{|c|}{ Despesa executada (R\$) } \\
\cline { 2 - 6 } & $\mathbf{2 0 1 4}^{*}$ & $\mathbf{2 0 1 5}$ & $\mathbf{2 0 1 6}$ & $\mathbf{2 0 1 7}$ & $\mathbf{2 0 1 8}$ \\
\hline \multirow{2}{*}{ Segurança Pública } & & $\begin{array}{c}8.094 .095 .148,00 \\
(67,96 \%)\end{array}$ & $\begin{array}{c}8.124 .997 .377,00 \\
(62,68 \%)\end{array}$ & $\begin{array}{c}8.084 .800 .133,00 \\
(60,59 \%)\end{array}$ & $\begin{array}{c}7.936 .126 .256,00 \\
(65,03 \%\end{array}$ \\
\hline
\end{tabular}

13 O Conselho de Acompanhamento e Controle Social (CACS) do FUNDEB é um colegiado que tem como função principal acompanhar e controlar a aplicação dos recursos do Fundo, no âmbito das esferas municipal, estadual e federal.

14 A classificação "função" é determinada como "áreas de ação governamental". Essa classificação vale para os três niveis de governo e foi instituida pela Portaria n ${ }^{\circ}$ 42, de 14 de abril de 1999, do então Ministério do Orçamento e Gestão. A classificação por funções e subfunções serve como um agregador dos gastos do governo, evidenciando a programação a partir de grandes áreas de atuação governamental. O que permitirá no caso especifico deste trabalho analisar o nivel de gastos com a função "Direitos de Cidadania", por exemplo, ou o nivel de gastos com a subfunção "custódia e reintegração social". 


\begin{tabular}{|c|c|c|c|c|}
\hline Previdência Social & $\begin{array}{c}3.501 .082 .684,00 \\
(29,40 \%)\end{array}$ & $\begin{array}{c}3.289 .433 .858,00 \\
(25.38 \%)\end{array}$ & $\begin{array}{c}3.858 .683 .703,00 \\
(28,92 \%)\end{array}$ & $\begin{array}{c}3.773 .383 .306,00 \\
(30,92 \%\end{array}$ \\
\hline $\begin{array}{l}\text { Direitos da Cida- } \\
\text { dania }\end{array}$ & $\begin{array}{c}206.965 .062,10 \\
(1,74 \%)\end{array}$ & $\begin{array}{c}1.433 .988 .610,00 \\
(11,06 \%)\end{array}$ & $\begin{array}{c}1.132 .128 .001,00 \\
(8,48 \%)\end{array}$ & $\begin{array}{c}254.286 .908,70 \\
(2,08 \%)\end{array}$ \\
\hline Administração & $\begin{array}{c}100.469 .638,50 \\
(0,84 \%)\end{array}$ & $\begin{array}{c}96.956 .666,35 \\
0,75 \%\end{array}$ & $\begin{array}{c}223.264 .156,40 \\
(1,67 \%)\end{array}$ & $\begin{array}{c}176.192 .455,20 \\
(1,44 \%)\end{array}$ \\
\hline Essencial à Justiça & $\begin{array}{c}7.008 .578,11 \\
(0,06 \%)\end{array}$ & $\begin{array}{c}8.995 .606,75 \\
(0,07 \%)\end{array}$ & - & - \\
\hline Encargos especiais & - & - & $\begin{array}{c}34.926 .003 .56 \\
(0,26 \%\end{array}$ & $\begin{array}{c}63.299 .904 .37 \\
(0,52 \%)\end{array}$ \\
\hline Outros & 93.314 .45 & $7.652 .107,71$ & $9.469 .671,23$ & 0,00 \\
\hline Total & $11.909 .714 .425,16$ & $12.962 .024 .225,81$ & $13.343 .271 .668,19$ & $12.203 .288 .830,27$ \\
\hline
\end{tabular}

Fonte: Site do Portal da Transparência: http://www.portaltransparencia.gov.br/orgaos. Ministério da Transparência e Controladoria geral da União, 2014 a 2018. Valores atualizados pelo INPC/IBGE de 01/2019. *Dados não mais disponíveis no portal da Transparência quando da realização da consulta em 27/02/2019.

Conforme evidenciado pela Tabela 8, os gastos com a função Direitos da Cidadania, ao longo da série histórica analisada, ampliaram a sua participação percentual e absoluta em relação ao total de gastos do Ministério da Justiça e Segurança Púbica. Essa ampliação chegou a septuplicar em 2016 e mais do que quintuplicou em 2017 passando a representar $11,06 \%$ e $8,48 \%$ dos gastos totais respectivamente. Em que pese o contexto de crise econômica, o aumento dos gastos com a função Direitos da Cidadania nesse período pode ser explicado pela aprovação, por parte do Supremo Tribunal Federal (STF), da Ação de Descumprimento de Preceito Fundamental (ADPF) $n^{\circ} 347$, que determinou o descontingenciamento das verbas do FUNPEN em 2015 e 2016 com repercussões positivas para os anos seguintes.

Contudo, esta ampliação não alterou o grau de importância desta função dentro do orçamento, mantendo-a como a terceira mais importante e, em 2017, sob a égide da EC n 95/2016, os recursos voltam a ser contingenciados por meio do Decreto no 8.961/2017 (Brasil, 2017), provocando vertiginosa queda dos gastos no ano de 2018, fazendo-os retornarem aos patamares dos gastos de 2015

No que se refere aos dados de receita corrente e receita executada do FUNPEN apresentados na Tabela 9, foi possivel perceber que:

TABELA 9 - Receitas correntes/previsto e executadas do FUNPEN - 2014 a 2018

\begin{tabular}{|c|c|c|c|}
\hline Ano & Receitas correntes/previsto & Receitas executadas & \% do executado/previsto \\
\hline 2014 & $647.185 .974,50$ & $404.685 .389,90$ & $62,53 \%$ \\
\hline 2015 & $677.938 .911,70$ & $412.475 .204,90$ & 60,84 \\
\hline 2016 & $757.984 .945,90$ & $411.607 .092,00$ & $54,30 \%$ \\
\hline 2017 & $730.135 .958,00$ & $378.718 .808,20$ & 51,87 \\
\hline 2018 & $591.714 .831,60$ & $132.747 .923,10$ & $22,43 \%$ \\
\hline
\end{tabular}

Fonte: Site do Portal da Transparência: http://www.portaltransparencia.gov.br/orgaos. Ministério da Transparência e Controladoria geral da União, 2014 a 2018. Valores atualizados pelo INPC/IBGE de 01/2019.

Houve ampliação das receitas correntes e das receitas executadas do FUNPEN ao longo dos anos de 2014 a 2017 e queda maior no ano de 2018 sob a vigência da EC nº 95/2016. No mesmo período, a média do percentual de receitas exe cutadas em relação ao previsto, ficou em torno $50,39 \%$ e, em 2018 , executou-se apenas $22,43 \%$ das receitas previstas.

Além dos constantes contingenciamentos, conforme revelado pelo Relatório Temático do 
FUNPEN (2017), a gestão dos recursos do FUNPEN é permeada por vícios e problemas no processo de planejamento na alocação de recursos e no atingimento dos objetivos do Fundo.

No que se refere aos dados de despesas exe- cutadas com recursos do FUNPEN com a função direitos de cidadania e a subfunção custódia e reintegração social, os dados da Tabela 10 revelaram que:

TABELA 10 - Despesas executadas com recursos do FUNPEN com a função Direitos da Cidadania por subfunção - 2014 a 2018

\begin{tabular}{|c|c|c|c|}
\hline \multirow{2}{*}{ Ano } & \multicolumn{2}{|c|}{ Subfunções } & \multirow{2}{*}{ Total função } \\
\cline { 2 - 3 } & Custodia e Reintegração social & Adm. Geral & $68.441 .390,09$ \\
\hline 2014 & $57.783 .794,14$ & 10.657 .595 .95 & $57.632 .280,01$ \\
\hline 2015 & $48.928 .585,47$ & 8.703 .694 .54 & 1.324 .456 .873 .53 \\
\hline 2016 & $1.317 .494 .654,00$ & $6.962 .219,53$ & $940.527 .358,09$ \\
\hline 2017 & $924.857 .986,10$ & $15.669 .371,99$ & $154.458 .227,42$ \\
\hline 2018 & $143.427 .110,50$ & $11.031 .116,92$ & \\
\hline
\end{tabular}

Fonte: Site do Portal da Transparência: http://wwww.portaltransparencia.gov.br/orgaos. Ministério da Transparência e Controladoria geral da União, 2014 a 2018. Valores atualizados pelo INPC/IBGE de 01/2019.

Durante o período analisado, os gastos com a subfunção reintegração social oscilaram ora para mais, ora para menos e representaram uma média girando em torno de $13 \%$ do total das receitas executadas com os recursos do fundo durante os anos de 2014 e 2015. Os gastos com a subfunção custódia e reintegração social - que abrange as atividades de formação educacional e cultural dos presos, elaboração e execução de projetos destinados à reinserção social de presos, internados e egressos, a realização de cursos técnicos, profissionalizantes e programas de alternativas penais à prisão - tiveram uma evolução positiva no período e, possivelmente em função do descontingenciamento dos recursos, alcançando o seu maior aumento nos anos de 2016 e 2017.

Contudo, os dados de despesa dos anos de 2016, 2017 e 2018 foram maiores que as receitas executadas no mesmo periodo, o que configura possivelmente um déficit orçamentário ou podem representar falhas no planejamento, processo de prestação de contas ou de execução dos recursos do fundo.

\section{Considerações finais}

Como vimos, o Sistema Penitenciário Brasileiro tem por objetivo efetivar as disposições de sentença ou decisão criminal e proporcionar condições para a harmônica integração social do condenado, não tem por objetivo se tornar um depósito de dejetos humanos. Vimos também que a educação é um direito constitucional universal a que deve fazer jus todas as pessoas, inclusive aquelas privadas de sua liberdade. Como direito, não pode ser tratada como benefício conferido ao preso por bom comportamento e deveria estar ao alcance de todos os apenados conforme determinado também pelo arcabouço legal que regulamenta o funcionamento das unidades prisionais no Brasil. Nesse sentido, ainda que com algumas limitações, a LEP delimita, de modo geral, um tratamento favorável à educação e, a reforma introduzida na mesma por meio da Lei n 12.433 , reforça essa tendência positiva.

A despeito de termos um aparato legal importante do ponto de vista da garantia dos direitos humanos, temos um sistema penitenciário com unidades prisionais em condições precárias, superlotadas, sem condições estruturais e de recursos humanos necessários para atender um público de privados de liberdade majoritariamente jovem e com baixa escolaridade.

Em que pese a importância do FUNPEN, fundo especíico para o financiamento do sistema prisional brasileiro no cumprimento de sua função principal de reintegração social do condenado, 
vem tendo sua existência marcada pelo aprovisionamento de recursos oriundo de transferências voluntárias e, por não decorrerem de obrigações estabelecidas constitucionalmente, vem sendo seguidamente contingenciado e consequentemente não aplicado nas finalidades previstas na legislação. Além disso, não possui um conselho de acompanhamento e controle social de seus recursos e apresenta problemas no processo de prestação de contas dos mesmos.

Em função disso, faz-se urgente que se constitua uma instância participativa colegiada para o acompanhamento e o controle social dos recursos do FUNPEN; alocar máxima prioridade na utilização das verbas do FUNPEN para o financiamento de políticas de alternativas penais, em projetos de educação regular; programas de profissionalização e oportunidades de trabalho a todas as pessoas presas, tanto fora como dentro de estabelecimentos penais.

Contudo, dado o cenário político e econômico atual orientado pelas medidas de congelamento de gastos com o setor social (saúde e educação) estabelecidas pela EC n 95/2016, e agora sob a égide da extrema direita no poder, as perspectivas não são nada animadoras para mudança positiva da realidade do sistema prisional brasileiro e de seu financiamento por meio do FUNPEN, visando o cumprimento de seu objetivo maior de reinserção social por meio da educação.

\section{Referências}

Brasil. (1964). Lei no 4.320: Estatui Normas Gerais de Direito Financeiro para elaboração e controle dos orçamentos e balanços da União, dos Estados, dos Municípios e do Distrito Federal. Presidência da República, Casa Civil, Subchefia para Assuntos Juridicos. http://WwW. planalto.gov.br/ccivil_03/leis/L4320.htm

Brasil. (1984). Lei de Execução Penal (LEP): Lei 7.210 de 11 de Julho de 1984. Presidência da República, Casa Civil, Subchefia para Assuntos Jurídicos. http://www. planalto.gov.br/ccivil_03/leis/L7210.htm

Brasil. (1988). Constituição Federal do Brasil. Presidência da República, Casa Civil, Subchefia para Assuntos Jurídicos. http://www.planalto.gov.br/ccivil_03/constituicao/constituicaocompilado.htm

Brasil. (1996). Lei no 9.394 de 20 de dezembro de 1996 Estabelece as Diretrizes e Bases da Educação Nacional. Presidência da República, Casa Civil, Subchefia para Assuntos Jurídicos. http://www.planalto.gov.br/ ccivil_03/Leis/L9394.htm
Brasil (2014). Levantamento Nacional de Informações Penitenciárias - InfoPen. Ministério da Justiça. Departamento Penitenciário Nacional. https://www.conjur. com.br/dl/infopen-dez14.pdf

Brasil. (2011). Decreto $n^{\circ} 7.626$, de 24/11/2011, que instituiu o Plano Estratégico de Educação no âmbito do Sistema Prisional (PEESP). Presidência da República, Casa Civil, Subchefia para Assuntos Jurídicos. http:// www.planalto.gov.br/CCIVIL_03/_Ato2011-2014/2011/ Decreto/D7626.htm

Brasil. (2011). Lei n 12.433, de 29 de junho de 2011. Altera a Lei no 7.210, de 11 de julho de 1984 (Lei de Execução Penal), para dispor sobre a remição de parte do tempo de execução da pena por estudo ou por trabalho. Presidência da República, Casa Civil, Subchefia para Assuntos Jurídicos. http://Www.planalto.gov.br/ccivil_03/_ato2011-2014/2011/lei/l12433.htm

Brasil. (2009). Resolução CNPCP no 03, de 11/03/2009, que dispõe sobre as Diretrizes Nacionais para a Oferta de Educação nos Estabelecimentos Penais. Conselho Nacional de Política Criminal e Penitenciária (CNPCP). http://portal.mec.gov.br/index.php?option=com_docman\&view=download\&alias $=10028$-resolucao-3-2009-secadi\&category_slug=fevereiro-2012-pdf\&ltemid $=30192$

Brasil. (2010). Resolução CNE no 2, de 19/05/2010, que dispõe sobre as Diretrizes Nacionais para a oferta de educação para jovens e adultos em situação de privação de liberdade nos estabelecimentos penais. Conselho Nacional de Educação. http://portal.mec. gov.br/index.php?option=com_docman\&view=download\&alias=5142-rcebo02-10\&category_slug=maio-2010-pdf\&Itemid=30192

Brasil. (2017). Relatório Temático: FUNPEN e Prevenção à Tortura - As ameaças e potenciais de um fundo bilionário para a prevenção à tortura no Brasil. Ministério de Direitos Humanos. Secretaria Nacional de Cidadania. Mecanismo Nacional de Prevenção e Combate à Tortura (MNPCT).

Brasil. (1994). Lei complementar $n^{\circ} 79$ de 07 de janeiro de 1994. Cria o Fundo Penitenciário Nacional - FUNPEN, e dá outras providências. http://Www. planalto.gov.br/ ccivil_03/LEIS/LCP/LCP7g.htm

Brasil. (2016). Resolução CNE n 4/2016, que dispõe sobre as Diretrizes Operacionais Nacionais para a remissão de pena pelo estudo de pessoas em privação de liberdade nos estabelecimentos penais do sistema prisional brasileiro. http://portal.mec.gov.br/index. php?option=com_docman\&view $=$ download \&alias $=-$ 42991-rceb004-16-pdf\&ltemid $=30192$

Brasil. (2016). Medida Provisória n 755/2016. Altera a Lei Complementar $n^{\circ} 79$, de 7 de janeiro de 1994, para dispor sobre a transferência direta de recursos financeiros do Fundo Penitenciário Nacional aos fundos dos Estados e do Distrito Federal, e a Lei $n^{\circ} 11.473$, de 10 de maio de 2007, que dispõe sobre a cooperação federativa no âmbito da segurança pública. https://Www.congressonacional.leg.br/materias/medidas-provisorias/-/ $\mathrm{mpv} / 127862$

Brasil. (2017). Medida Provisória $n^{\circ}$ 781, de 23 de maio de 2017. Altera a Lei Complementar $n^{\circ} 79$, de 7 de janeiro de 1994, para dispor sobre a transferência de 
recursos financeiros do Fundo Penitenciário Nacional, e a Lei $n^{\circ} 11.473$, de 10 de maio de 2007. http://Www2. camara.leg.br/legin/fed/medpro/2017/medidaprovisoria-781-23-maio-2017-784921-publicacaooriginal-152804-pe.html

Erdelyi, M. F. (2017, Dez. 8). Brasil dobra número de presos em 11 anos. G1: Politica. https://g1.globo.com/ politica/noticia/brasil-dobra-numero-de-presos-em-11-anos-diz-levantamento-de-720-mil-detentos-40-nao-foram-julgados.ghtml

Fidalgo, F., Fidalgo, N., Rocha, S. W., \& Alves, Y. E. (2017) O ONASP e a produção acadêmica sobre o Sistema Prisional Brasileiro In Fidalgo, F., \& Fidalgo, N. (Orgs.), Sistema Prisional: teoria e Pesquisa (pp. 17-40). Editora UFMG.

Gomes, A. V. A. (2016). Oferta educacional em prisões e a modalidade de educação a distância. Câmara dos Deputados, Estudo Técnico.

Mancebo, D. (2017). Crise Político-Econômica no Brasil: Breve Análise da Educação Superior. Educ. Soc., 38(141), 875-892. http://Www.scielo.br/pdf/es/v38n141/16784626-es-es0101-73302017176927.pdf

Menezes, A. M., \& Veroneze, R. T. (2011). O papel do fundo penitenciário nacional no desenvolvimento das políticas públicas frente à questão social presente no sistema prisional feminino. Anais do / Circuito de debates acadêmicos, IPEA-CODE. https://carceropolis.org.br/ static/media/publicacoes/O_papel_do_Funpen_no_ desenvolvimento_das_politicas_públicas.pdf

Organização dos Estados Americanos. (1988). Protocolo Adicional à convenção Americana sobre direitos econômicos, sociais e culturais, de 17 de novembro de 1988. Protocolo de San Salvador. http://Www.direito.mppr. $\mathrm{mp}$.br/arquivos/File/protocoloadicional.PDF

Organização das Nações Unidas. (1948). Resolução $n^{\circ}$ 217 da Assembleia Geral das Nações Unidas, de 10 de dezembro de 1948. Declaração Universal dos Direitos Humanos. https://www.unicef.org/brazil/pt/resources_10133.htm

Santos, T. M. dos, \& Rodrigues, M. da S. e C. (2017). Gasto público com o sistema prisional: a despesa do Estado de Minas Gerais com o encarceramento feminino. In Fidalgo, F., \& Fidalgo, N. (Orgs.), Sistema Prisional: teoria e Pesquisa (p. 225-251). Editora UFMG.

Souza, I. (2017, Fev. 14). Quanto custa um preso no Brasil? Politize! https://www.politize.com.br/quanto-custa-preso-no-brasil

Viana, L. C. (2017). Trabalho e Educação como instrumentos de Emancipação nas prisões. In Fidalgo, F., \& Fidalgo, N. (Orgs.), Sistema Prisional: teoria e Pesquisa (pp. 93-116). Editora UFMG.

\section{Fabrício Aarão Freire Carvalho}

Doutor em Educação pela Universidade de São Paulo (USP), em São Paulo, SP, Brasil. Professor do Núcleo de Estudos Transdisciplinares em Educação Básica (NEB) da Universidade Federal do Pará (UFPA), em Belém, PA, Brasil.

\section{Maria do Socorro da Costa Coelho}

Doutora em Educação pela Pontifícia Universidade Católica de São Paulo (PUC), em São Paulo, SP, Brasil. Professora Associada da Universidade Federal do Pará (UFPA), em Belém, PA, Brasil.

\section{Pablo Aguiar Castro Batista}

Mestre em Currículo e Gestão da Escola Básica pela Universidade Federal do Pará (UFPA), em Belém, PA, Brasil.

\section{Endereço para correspondência}

Fabrício Aarão Freire Carvalho/ Maria do Socorro da Costa Coelho

Universidade Federal do Pará

Rua Augusto Correa, 01

Guamá, 66070-110

Belém, Pará, Brasil

Os textos deste artigo foram revisados pela Poá Comunicação e submetidos para validação do(s) autor(es) antes da publicação. 